\title{
MOBILIDADE DE CÁTIONS EM ALTERAÇÃo INTEMPÉRICA DE DIABÁSIO NO MUNICÍPIO DE RIO DAS PEDRAS, SP
}

A. MARCONI ${ }^{1}$

RESUMO: Em uma sequência de alteração intempérica de diabásio, é estudada a mobilidade dos principais cátions, desde a rocha não alterada até o solo de origem. Da rocha primitiva, apenas cerca de $44 \%$ de material sólido permanecem na fase final, constituindo a fração detrítica do solo. A eliminação dos cátions solúveis é rápida e ocorre nas primeiras fases da alteração. A silica, removida mais lentamente, tem cerca de $60 \%$ eliminada, permanecendo no solo o alumínio, o ferro e parcialmente o titânio. Termos para indexação: diabásio, intemperização de rochas

\section{CATION MOBILITY IN WEATHERING ALTERATION OF DIABASE IN RIO DAS PEDRAS-SP COUNTY}

ABSTRACT: The mobility of the principal cations of a diabase is studied in a weathering sequence, from unaltered rock to the rockderived soil. From the original rock, just about $44 \%$ of the original rock material remains in the final fase, making up the detrital fraction of the soil. Elimination of the soluble cations is fast and occurs in the early weathering stages. Silica, which is removed at a slower rate is eliminated up to about $60 \%$ of the original rock content, while aluminium, iron and titanium stay in the soil.

Index terms: diabase, rock weathering.

1 Departamento de Solos, Geologia e Fertilizantes-ESALQ/USP. 


\section{INTRODUÇĀo}

Os processos de alteração de rochas basálticas têm originado os solos mais ferteis, encontrados no sul do Brasil, dentro da Bacia Geológica Sedimentar do Paraná. Essas alteraçōes têm motivado a atenção de diversos pesquisadores, que estudaram tanto a geoquímica como a mineralogia envolvidas no processo (MELFI \& LEVI, 1971; LEVI \& MELFI, 1972; MONIZ et alii, 1973; FORMOSO \& PINTAUDE, 1978; MENEGOTO, 1983). Rochas básicas de outras regiões brasileiras, situadas em condições climáticas diferentes das que ocorrem na Bacia do Paraná, tiveram seus processos de alteração estudados por OLIVEIRA \& TRESCASES (1980), no Brasil Central (Goiás) e por LEMOS \& VILLAS (1983), na regiào norte (Pará).

$\mathrm{Na}$ depressão periférica do Estado de São Paulo, a remoção do basalto, devido à processos de intemperização e erosão, expos o diabásio, na forma de sills e diques, que, por sua vez, originaram solos de alta fertilidade. A região de Piracicaba, da qual o município de Rio das Pedras é parte integrante, é particularmente rica nessas intrusões diabásicas, que até agora não foram devidamente estudadas quanto as alteraçōes emtempéricas que apresentam. A exposição de uma intrusão dessas, mostrando uma sequência de alteração intempérica, desde a rocha não alterada até o solo permitiu, neste trabalho, o estudo da mobilidade dos cátions durante o processo de intemperização do diabásio. 


\section{MATERIAL E MÉTODOS}

Material

As amostras foram coletadas no município de Rio das Pedras, SP, na estrada do Açú-

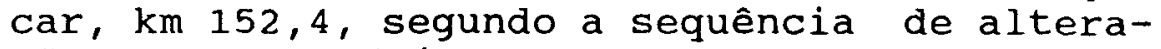
ção que segue (figura 2):

Amostra 1: rocha integra, sem sinais de decomposição.

Amostra 2: rocha mostrando processo de decomposição.

Amostra 3: material resultante de decomposição, situado em região com matacões de diabásio.

Amostra 4: material resultante de decomposição, situado em região sem matacões de diabásio.

Amostra 5: horizonte $\mathrm{C}$ do solo.

Amostra 6: horizonte B do solo.

Métodos

A mineralogia da rocha não alterada foi estudada em lâminas de seção delgada, através de microscopia ótica de polarização, que permitiu, por contagem de pontos, a determinação quantitativa dos minerais presentes.

As amostras sofreram fusão $\operatorname{com~} \mathrm{Na}_{2} \mathrm{CO}_{3}$, para análise de ferro total, cálcio, magnésio (espectrofotometria de absorção atômica), potássio (fotometria de chama), titânio (colorimetria), alumínio (volumetria) e silica 

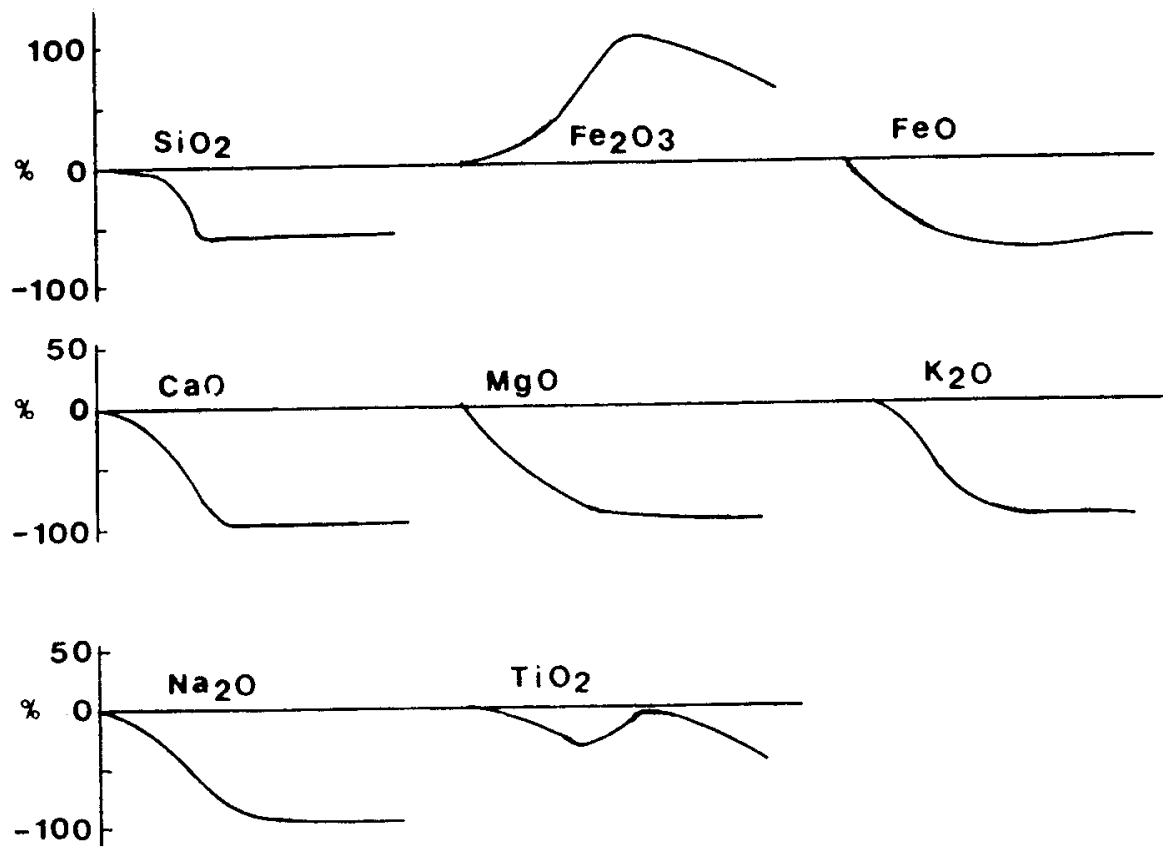

Figura 1 - Curvas de ganhos e perdas (\%) dos óxidos, nas fases de alteração. 


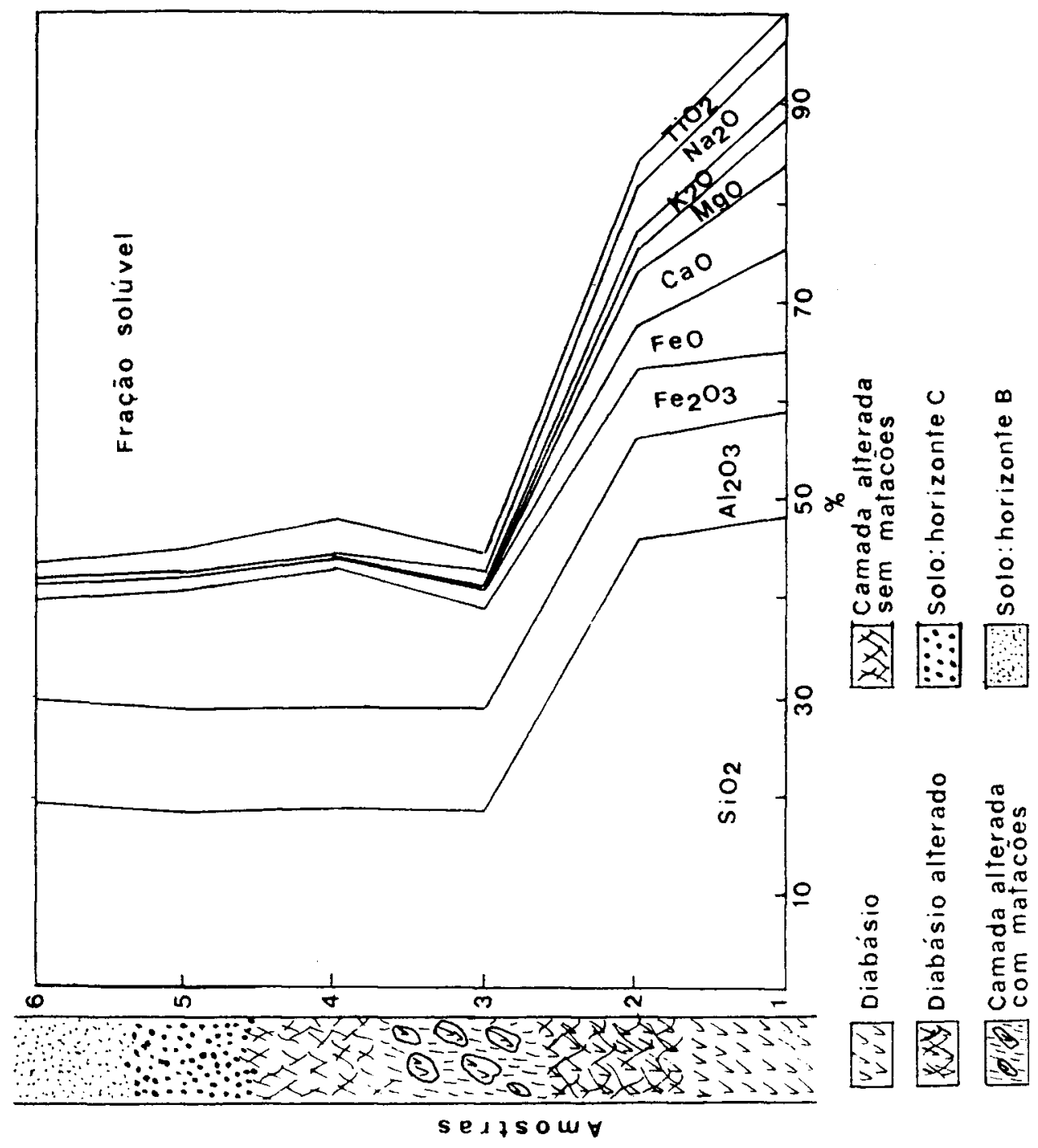

Figura 2 - Evolução quantitativa de óxidos, nas fases de alteração (método do isoalumínio). 
(gravimetria). o sodio foi determinado por fotometria de chama, após ataque sulfúrico das amostras e o ferro bivalente por volumetria, após ataque nitroperclórico. O ferro trivalente foi calculado por diferença entre o ferro total e o bivalente.

A avaliação da mobilidade dos constituintes, durante o processo de alteração, foi efetuada recalculando-se, pelo método do isoaluminio, os valores encontrados, partindo da suposição de que os teores de aluminio não mudam de maneira significativa durante o intemperismo, por ser este elemento imobilizado no sistema, precipitado na forma de $\mathrm{Al}_{2} \mathrm{O}_{3}$ (KRAUSKOPF, 1972). Desse modo, pode-se considerar, com pouca margem de erro, que a quantidade absoluta de alumínio que existe na rocha não alterada é a mesma que ocorre no solo (GOLDISH, 1938; MONIZ et al., 1973), o que permite calcular as quantidades absolutas dos outros elementos, nas diversas etapas do processo de intemperismo. Esse método possibilita avaliar a mobilidade dos constituintes originais da rocha, durante o intemperismo, bem como calcular o residuo detrítico remanescente no solo.

Caracterização da Área

o diabásio estudado pertence à formação Serra Geral, exposto à superficie devido a processos pretéritos de denudação, estando embutido em sedimentos do grupo Tubarão, onde localmente predominam folhelhos e siltitos. A situação topográfica atual é de meia encosta, com declive acentuado, apresentando boas condiçōes de drenagem e de escoamento superficial de água.

o clima da região é, segundo o sistema de Koppen, do tipo Cwa, mesotérmico de inverno seco, com temperaturas médias minimas inferio- 
res a $18^{\circ} \mathrm{C}$ e máximas superiores a $22^{\circ} \mathrm{C}$. O regime de umidade é údico, com Índice pluviométrico anual entre 1100 e $1700 \mathrm{~mm}$ (COMISSÃO DE SOLOS, 1960).

\section{RESULTADOS E DISCUSSÃo}

o diabásio é de granulação fina, contendo $38,4 \%$ de plagioclásios calco-sódicos, $34,3 \%$ de piroxênios (augita associada a pigeonita), 15,6\% de minerais opacos (ilmenita $e$ magnetita) e $11,7 \%$ de outros minerais, principalmente biotita. A disposição dos grânulos indica que os plagioclásios formaram-se antes dos piroxênios e estes antes dos minerais opacos.

Os resultados apresentados nas tabelas 2 e 3 foram utilizados para a construção dos gráficos 1 e 2, a fim de facilitar a visualização da variação de composição química das diversas fases de evolução do intemperismo. Os dados expressos nas tabelas 1 e 2 mostram que a alteração do diabásio tem inicio nos minerais ferromagnesianos, demonstrada pela perda inicial mais elevada de Mgo e de Feo, este parcialmente removido do sistema e, em sua maior parte, oxidado a $\mathrm{Fe}_{2} \mathrm{O}_{3}$. A decomposição dos plagioclásios se faz mais lentamente no inicio do processo, o que se verifica por uma perda inicial mais lenta de $\mathrm{CaO} e$ de $\mathrm{Na}_{2} \mathrm{O}$, mas que após a primeira fase (amostra 2), torna-se bastante intensa. Na amostra 3 os minerais primários mais rapidamente intemperizáveis, plagioclásios e ferromagnesianos, praticamente já não mais existem, uma vez que os cátions solúveis, cálcio, magnésio, sódio e potássio foram quase totalmente lixiviados, ocorrendo em teores não expressivos, em torno de $1 \%$ ou menos. Na amostra 4 , a perda de cations solúveis é sempre superior a $99 \%$, em relação ao teor existente na rocha não alterada. A figura 1 
rabela 1. Composiçăo química das fases de alteraçăo, com valores reajustados a $100 \%$.

\begin{tabular}{ccccccccccc}
\hline Amostra & SiO2 & A1203 & Fe203 & FeO & CaO & MgO & K2O & Na20 & TiO2 & Total \\
\hline 1 & 48.56 & 10.50 & 6.33 & 10.39 & 8.48 & 4.60 & 2.14 & 5.82 & 3.18 & 100.00 \\
2 & 54.44 & 12.47 & 8.33 & 5.23 & 6.91 & 2.33 & 2.02 & 5.10 & 3.17 & 100.00 \\
3 & 41.29 & 23.46 & 22.72 & 3.22 & 0.18 & 0.82 & 0.71 & 3.07 & 4.53 & 100.00 \\
4 & 39.38 & 22.00 & 28.73 & 2.43 & 0.15 & 0.26 & 0.09 & 0.43 & 6.53 & 100.00 \\
5 & 40.98 & 23.22 & 26.56 & 2.88 & 0.19 & 0.22 & 0.11 & 0.33 & 5.51 & 100.00 \\
6 & 44.53 & 24.08 & 23.40 & 3.31 & 0.29 & 0.21 & 0.08 & 0.35 & 3.75 & 100.00 \\
\hline
\end{tabular}

Tabela 2. Composição química das fases de alteraçăo, calculada pelo metodo do isoalumínio (\$).

\begin{tabular}{lcccccccccc}
\hline Amostra & SiO2 & Al2O3 & Fe2O3 & FeO & CaO & Mgo & K2O & Na2O & TiO2 & Total \\
\hline 1 & 48.56 & 10.50 & 6.33 & 10.39 & 8.48 & 4.60 & 2.14 & 5.82 & 3.18 & 100.00 \\
2 & 45.84 & 10.50 & 7.01 & 4.40 & 5.82 & 1.96 & 1.70 & 4.29 & 2.67 & 84.20 \\
3 & 18.48 & 10.50 & 10.17 & 1.44 & 0.08 & 0.37 & 0.32 & 1.37 & 2.03 & 44.76 \\
4 & 18.80 & 10.50 & 13.71 & 1.16 & 0.07 & 0.12 & 0.04 & 0.21 & 3.12 & 47.73 \\
5 & 18.53 & 10.50 & 12.01 & 1.30 & 0.09 & 0.10 & 0.05 & 0.15 & 2.49 & 45.22 \\
6 & 19.42 & 10.50 & 10.20 & 1.44 & 0.13 & 0.09 & 0.03 & 0.15 & 1.64 & 43.60 \\
\hline
\end{tabular}

Tabela 3. Ganhos e perdas (z) de oxidos, nas fases de alteraçăo, calculados pelo método do isoaluminio.

\begin{tabular}{crrrrrrrr}
\hline Amostra & SiO2 & Fe2O3 & FeO & CaO & MgO & K2O & Na2O & TiO2 \\
\hline 2 & -5.6 & 10.8 & -57.6 & -31.4 & -57.3 & -20.5 & -26.2 & -16.1 \\
3 & -61.9 & 60.6 & -86.1 & -99.0 & -92.0 & -85.2 & -76.4 & -36.2 \\
4 & -61.3 & 116.6 & -88.8 & -99.2 & -97.3 & -98.0 & -96.5 & -2.0 \\
5 & -61.8 & 89.7 & -87.5 & -99.0 & -97.8 & -97.7 & -97.4 & -21.6 \\
6 & -60.0 & 61.2 & -86.1 & -98.5 & -98.0 & -98.4 & -97.4 & -48.6 \\
\hline
\end{tabular}


permite observar o comportamento desses cátions, na intemperização do diabásio. Mgo e Feo apresentam curvas de perdas semelhantes, com tendência à rápida perda inicial e posterior estabilização, ao contrário de CaO, $\mathrm{K}_{2} \mathrm{O}$ e $\mathrm{Na}_{2} \mathrm{O}$, que mostram perda inicial menor, para sofrer um incremento altamente intenso, a partir da segunda fase de alteração. Pode-se estabelecer, então, que no inicio da intemperização, a remoção de cátions segue a sequência

$$
\mathrm{FeO}>\mathrm{MgO}>\mathrm{CaO}>\mathrm{Na}_{2} \mathrm{O}>\mathrm{K}_{2} \mathrm{O}
$$

A partir da segunda fase, a remoção de bases passa a ser

$$
\mathrm{CaO}>\mathrm{MgO}>\mathrm{FeO}>\mathrm{K}_{2} \mathrm{O}>\mathrm{Na}_{2} \mathrm{O}
$$

Esses resultados mostram-se discrepantes com os apresentados por HYPOLITO \& VALARELLI (1973), que encontraram mobilidade de $\mathrm{K}$ e $\mathrm{Na}$ maior que de $\mathrm{Mg}$ e $\mathrm{Fe}$, em estudos de alteração de diabásios, mas concordam com os encontrados por ANDERSON \& HAWKES (1958), quanto à maior mobilidade de $\mathrm{Ca} e \mathrm{Mg}$ e menor de $\mathrm{K}$.

Deve-se considerar que a remoçăo de Feo do sistema é apenas parcial, uma vez que sua oxidação a $\mathrm{Fe}_{2} \mathrm{O}_{3}$ é a via preferencial de redução de seu teor. Na amostra 2 (tabela 2), observa-se que $O$ aumento no teor de $\mathrm{Fe}_{2} \mathrm{O}_{3}$ é menor que a diminuição verificada no teor de Feo, mostrando que, além da oxidação, também uma parte do $\mathrm{Fe}^{2+}$ foi lixiviada.

o comportamento da silica segue em princípio o de CaO, $\mathrm{Na}_{2} \mathrm{O}$ e $\mathrm{K}_{2} \mathrm{O}$, com remoção mais lenta na primeira fase e um grande incremento posterior, o que mostra ser a silica também um constituinte solúvel e facilmente lixiviado. Seu teor inicial elevado, todavia, faz com que, no final do processo, exista silica em quantidade razoável no sistema residual. Embora não tenham sido identificados 
os minerais presentes nas fases de alteração, é possivel afirmar que essa silica seja constituinte de argilominerais 1:1. Também, a pouca ocorrência de cálcio, magnésio, sódio e potássio induz a conclusão de que não ocorrem minerais de estrutura 2:1 nas fases finais do processo de alteração (MELFI \& PEDRO, 1977). os óxidos considerados insolúveis, $\mathrm{Al}_{2} \mathrm{O}_{3}$ e $\mathrm{Fe}_{2} \mathrm{O}_{3}$ confirmam esse comportamento, com teores superiores nas amostras intemperizadas (tabela 1). O aumento de $\mathrm{Al}_{2} \mathrm{O}_{3}$ é apenas relativo e deve ser considerado apenas em função da diminuição dos teores dos outros óxidos, mas o mesmo não pode ser dito com relação ao $\mathrm{Fe}_{2} \mathrm{O}_{3}$, cujo aumento real no teor se faz principalmente como consequência da oxidação do $\mathrm{Fe}^{2+}$ (tabela 2 e figura 1).

A tabela 2 e a figura 2 mostram que, do material sólido original, apenas $43,5 \%$ permanecem no solo, constituindo a fração solúvel lixiviada $56,5 \%$ do total. A lixiviação da fração solúvel eliminou, além da quase totalidade das bases solúveis, cerca de $60 \%$ da silica originalmente existente na rocha e apenas $\circ \mathrm{Fe}_{2} \mathrm{O}_{3}$ teve ganho real nas amostras alteradas, comparando-se com os teores originais da rocha não alterada.

\section{REFERÊNCIAS BIBLIOGRÁFICAS}

ANDERSON, D.H. \& HAWKES, H.E. Relative mobility of the common elements in weathering of some schist and granite areas. Geochimica et Cosmochimica Acta, London 14 (3): 204-210, 1958 .

COMISSÃo DE SOLOS. Levantamento de reconhecimento dos solos do Estado de São Paulo. Boletim do Servico Nacional de Pesquisas Agronômicas, São Paulo (12): 1-605, 1960. 
FORMOSO, M.L.L. \& PINTAUDE, D.A. Estudo da alteração do anortosito de Capivarita, Rio Pardo, R. S. Revista Brasileira de Geociências, São Paulo $\underline{8}(3): 180-205,1978$. GOLDISH, S.S. A study in rock-weathering. Journal of Geology., Chicago, 46 : 17-58, 1938 .

HYPOLITO, R. \& VALARELLI, J.V. Ordem de remoção de elementos lixiviados em experiências de alteração. Boletim IG, Instituto de Geociências, são Paulo, 4: $47-51,1973$.

KRAUSKOPF, K. B. Introdução à Geoquímica. São Paulo, EDUSP, Polígono, 1972. v.1.

LEMOS, V.P. \& VILLAS, R.N. Alteração supérgena das rochas básicas do grupo Grão Pará - Implicaçōes sobre a gênese do depósito de bauxita de N5, Serra dos Carajás. Revista Bras. de Geociências, São Paulo $\underline{13}$ (3): 165-77, 1983.

LEVI, F. \& MELFI, A.J. Geochemical and mineralogical studies on the first stages of weathering of basic and related rocks. Revista Brasileira de Geociências, São Paulo $\underline{2}$ (1): 1-7, 1972 .

MELFI, A.J. \& LEVI, F. Geochemical and mineralogical study on the first stages of weathering of basic and related rocks. Revista Brasileira de Geociências, são Paulo 1 (1): 22-8, 1971.

MELFI, A.J. \& PEDRO, G. Estudo geoquímico dos solos e formaçōes superficiais do Brasil. Revista Bras. de Geociências, São Paulo 7 (4): 271-286, 1977. 
MENEGOTTO, E. Intemperização de rochas ultrabásicas no Rio Grande do Sul, Brasil. Revista Brasileira de Geociências, São Paulo 13 (3): 178-89, 1983 .

MONIZ, A.C.; NASCIMENTO, A.C; PAIVA NETTO, J. E. Mobilidade dos constituintes de rochas básicas de São Paulo durante o intemperismo. Revista Brasileira de Geociências, São Paulo, 3 (3): 201-13, 1973 .

OLIVEIRA, S.M.B. \& TRESCASES, J.J. Geoquímica da alteração supérgena das rochas ultramáficas de santa fé (Goiás, Brasil). Revista Brasileira de Geociências, São Paulo 10 (4), 243-57, 1980 .

Trabalho entregue para publicação em 28.12.89 Trabalho aprovado para publicação em 08.02.91 